\title{
A Note from the Editor
}

As 2015 draws to a close, I am excited to introduce a brand new look for Education Libraries. When I took over editorship of the journal, I hoped to continue publishing interesting and relevant content but in an updated and more reader-friendly package. The new Open Journal Systems (OJS) interface, will not only provide a better userexperience but will also allow for a more streamlined publication process for authors, peer-reviewers and editors alike.

The need to evolve with the changing times is a prevalent theme in librarianship today. The research articles featured in this issue speak to the challenges that libraries face today challenges that often necessitate change. Rita Kohrman examines the impact of economic and academic difficulties on Michigan's Curriculum Materials Centers and Collections, while Elizabeth Burns explores how school librarians must advocate for their positions and their library programs.

This issue features a new section for Education Libraries: The Member Profile. Our first profile features an interview with Lesley Farmer, recipient of the 2015 Anne Galler award. In coming issues we will bring you profiles of other members of SLA's Education Division, to build connections between members despite geographic distance.

The publication of this issue would not have been possible without the help of a fantastic editorial team of peer reviewers and copy editors.

\section{The 2015 Editorial Team:}

Savika Fowsar

Jim Kelly

Jessica Lange

Maura McGrath

Nikki Tummon,

Education Libraries is looking for a new book review editor. If you are interested in this role, please contact Katherine Hanz at education.libraries@gmail.com.

Enjoy this issue of Education Libraries, and do send comments, questions and submissions to education.libraries@gmail.com

Happy New Year!

Katherine

Katherine Hanz

Humanities \& Social Sciences Library

McGill University

Montreal, Quebec, Canada

Education.libraries@gmail.com

katherine.hanz@mcgill.ca 